\title{
The $\beta$-Cell Genomic Landscape in T1D: Implications for Disease Pathogenesis
}

\author{
Mireia Ramos-Rodríguez ${ }^{1} \cdot$ Beatriz Pérez-González ${ }^{1} \cdot$ Lorenzo Pasquali $^{1}$
}

Accepted: 19 November 2020 / Published online: 2 January 2021

(C) The Author(s) 2021

\begin{abstract}
Purpose of Review Type 1 diabetes (T1D) develops as a consequence of a combination of genetic predisposition and environmental factors. Combined, these events trigger an autoimmune disease that results in progressive loss of pancreatic $\beta$ cells, leading to insulin deficiency. This article reviews the current knowledge on the genetics of T1D with a specific focus on genetic variation in pancreatic islet regulatory networks and its implication to T1D risk and disease development.

Recent Findings Accumulating evidence suggest an active role of $\beta$ cells in T1D pathogenesis. Based on such observation several studies aimed in mapping T1D risk variants acting at the $\beta$ cell level. Such studies unravel T1D risk loci shared with type 2 diabetes (T2D) and T1D risk variants potentially interfering with $\beta$-cell responses to external stimuli.

Summary The characterization of regulatory genomics maps of disease-relevant states and cell types can be used to elucidate the mechanistic role of $\beta$ cells in the pathogenesis of T1D.
\end{abstract}

Keywords Type 1 diabetes $\cdot$ Beta cells $\cdot$ Pancreatic islets $\cdot$ Regulatory genomics $\cdot$ Human genetics $\cdot$ Epigenomics

\section{Introduction}

Type 1 diabetes (T1D) is the most common form of diabetes in childhood, accounting for approximately $75 \%$ of diabetes new diagnoses in patients $\leq 19$ years of age. In North America and Europe, the incidence of T1D varies between 4 and 41 per 100,000 , with approximately $>17,000$ new cases occurring annually in the USA [1-3].

T1D is a chronic autoimmune disease that develops from the interaction of genetic and environmental factors [4]. Combined, these factors trigger an aggressive autoimmune assault against pancreatic $\beta$-cells, provoking local inflammation of pancreatic islets (insulitis) and progressive loss of $\beta$ cells $[5,6]$. Genetic and non-genetic factors likely operate at

Mireia Ramos-Rodríguez and Beatriz Pérez-González contributed equally to this work.

This article is part of the Topical Collection on Pathogenesis of Type 1 Diabetes

Lorenzo Pasquali

lorenzo.pasquali@upf.edu

1 Endocrine Regulatory Genomics, Department of Experimental \& Health Sciences, University Pompeu Fabra, 08003 Barcelona, Spain all stages of this process [7]. Currently, our knowledge about the molecular mechanisms linking genetic variation and environmental triggers with T1D remains limited.

The disease develops upon inheritance of an adaptive immune system genetically prone to respond to $\beta$-cell antigens [8]. In this context, autoreactive $T$ cells that have escaped central tolerance drive the destruction of $\beta$-cells through cytokine-mediated mechanisms and direct human leukocyte antigen (HLA) class I cytotoxic killing [9]. Growing evidence points to an intrinsic, genetically determined, $\beta$-cell vulnerability to cell death, as a central mechanism driving T1D pathogenicity. Understanding the genetic basis of $\beta$-cell vulnerability in T1D holds the promise to solve critical disease mechanisms that could, in turn, be the target of new therapeutic approaches.

These review overviews research deciphering disease mechanisms using genetic approaches with a focus on the implication for the $\beta$-cells in T1D pathogenesis.

\section{Deciphering the Genetic Component of T1D}

The exact mechanisms that trigger the $\beta$-cell-targeted autoimmune attack are not fully understood. In line with a 
multifactorial aetiology, T1D presents a non-Mendelian inheritance pattern, showing a strong heritable component supported by up to $70 \%$ twin concordance [10] and sibling risk around $8 \%[11,12]$.

In monogenic diseases, DNA sequencing has greatly improved clinical practice and genetic counselling through the identification of causal genes. This advance has in turn helped to clarify the disease pathogenesis, thus, opening the path to the development of new treatments or the use of etiologically directed drugs [13]. In complex or multifactorial diseases, the pathway to personalized medicine is more challenging and requires deciphering of a complex genetic architecture underlying broad and heterogeneous clinical spectra [14]. The detection of genetic association signals, often driven by common low-impact risk variants, offers the opportunity to gain mechanistic insight into the disease pathogenesis and shed light on the key genes implicated in the development of T1D.

Additionally, trait-associated genetic variants may be useful to identify individuals who are at higher risk of developing a specific disease. This concept underlies the development of polygenic risk scores (PRS), used to describe the overall genetic risk of a given individual, based on the combination of all variants, including genetic signal with modest effect size, associated to a disease [15]. Thus, each variant is weighted according to its contribution and effect direction [16]. In T1D, PRS offers the opportunity of using disease prediction for a more meticulous surveillance of atrisk individuals or for contemplating their inclusion into trials of early immunological intervention [7]. As an example, Sharp et al. [17] successfully developed a PRS based on 67 different SNPs, including both HLA DR-DQ haplotypes and non-HLA variants. This study allowed discrimination of T1D candidates with outstanding accuracy, performing 50\% better than other PRS in T1D prediction when applied to general population. However, most genetic studies are performed in populations with European ancestry, leading to an increased risk of misdiagnosing or misclassifying in underrepresented populations, as the transferability of the same PRS between populations is low $[12,18]$.

The strong commitment of families with affected members to genetic research efforts has allowed to gain insights into the genetic architecture of T1D and, to some extent, to develop disease prediction based on patient's genetic background [7].

\section{T1D Genetic Risk Factors}

During the last decades, large efforts have been dedicated to genotyping and analysis of thousands of human genomes with the aim of finding DNA variants associated with complex diseases as well as common traits. These studies, known as GWAS (genome-wide association studies), have revealed more than 60 regions that influence T1D risk, explaining almost $80 \%$ of disease heritability $[19,20]$.

As for other complex diseases, the overall influence of the genetic background in T1D results from the contribution of genomic variants that (with the remarkable exception of the human leukocyte antigen (HLA) region) individually exert a modest effect and have a small impact on the clinical outcome. While HLA-associated variants were the first to be reported [21] and show the highest impact on T1D risk [22], non-HLA loci include common, low-impact associated variants, possibly affecting the disease progression and the speed at which functional $\beta$-cell mass is lost $[23,24]$.

\section{HLA Loci}

The highly polymorphic HLA region on chromosome 6p21 encodes for glycoproteins belonging to the major histocompatibility complex (MHC). These molecules interact with peptide antigens, allowing the immune cells to recognize non-self antigens and trigger an immune response. The HLA region is strongly associated with T1D, accounting for approximately $50 \%$ of the overall heritability [25].

HLA class II genes (HLA-DP, HLA-DQ and HLA-DR) code for proteins expressed by antigen-presenting cells (APCs). Approximately, 90\% of T1D cases present HLA class II risk haplotypes with variants conferring the strongest susceptibility being located at highly polymorphic sites, encoding for the peptide-binding pockets of the DQ and DR molecules [26, 27]. For example, in Caucasians, common haplotypes conferring susceptibility to T1D are those that encode for the DR4/DQ8 and DR3/DQ2 molecules, thus associating HLA-DQ2/DQ8 with higher risk of T1D (with an odds ratio of almost 11). On the other hand, another haplotype in this region, coding for the DQ6 molecule, is associated with a protective role [12].

In addition to HLA class II risk variants, genetic association to T1D was also found at the HLA class I region, particularly in HLA-A and HLA-B [26, 27]. Classical HLA class I genes (HLA-A, HLA-B and HLA-C) encode for proteins that have a critical role in cytotoxic $\mathrm{CD} 8^{+} \mathrm{T}$ cell-mediated activity, the main mechanism of T1D-associated autoimmunity. This locus also contains other non-classical HLA class I genes, such as HLA-E, which encodes for proteins involved in antigen presentation to natural killer (NK) cells $[28,29]$. It is likely that risk alleles at these genomic loci influence $\beta$-cell destruction and T1D progression. Indeed, HLA-A*24 allele is associated with low residual $\beta$-cell function, possibly due to an enhanced immune-mediated destruction of insulinproducing cells in individuals carrying the risk haplotype. Other examples of variants in class I HLA genes that modulate T1D genetic risk in both directions have been reviewed in more detail elsewhere [22, 29].

\section{Non-HLA Loci}

The first non-HLA genetic signals associated with T1D were obtained from small candidate gene association studies and 
family linkage analyses. Such studies often had small sample sizes and were thus underpowered, but allowed to identify several key candidate genes outside the HLA locus.

The $5^{\prime}$ upstream region of the insulin locus (INS) is the second genomic region with strongest association with T1D risk (about 10\% contribution to T1D susceptibility) [23] and the first non-HLA locus to be associated with T1D [30]. In particular, most genetic association comes from the variable number of tandem repeats in this locus (INS-VNTR). The VNTR alleles are classified according to their length, and shorter alleles (class I) have been associated with an increased risk of T1D by influencing the expression of (pro)insulin in the thymus. This is an example of an allele-specific mechanism that helps to capture the complexity of T1D-associated genetic risk [31]. In contrast, long VNTR alleles (class III) seem to confer protection against T1D, as they were shown to promote higher levels of insulin transcription in the thymus during the induction of central immune tolerance [23, 32, 33].

The CTLA4 locus has also been associated with T1D, although this relationship varies across different ethnic populations. CTLA4 is a known extracellular receptor that is a negative regulator of cytotoxic $\mathrm{CD} 8^{+} \mathrm{T}$ cell immune responses [34-36]. Additional loci initially associated to T1D prior to application of GWAS include protein tyrosine phosphatase, non-receptor type 22 (PTPN22) gene [37, 38], interleukin 2 receptor alpha $(I L 2 R A)[39,40]$, ubiquitin-associated and $\mathrm{SH} 3$ domain-containing protein $\mathrm{A}(U B A S H 3 A)$ [41] and interferoninduced helicase $\mathrm{c}$ domain-containing protein 1 (IFIH1) [33, 42].

The application of GWAS together with their metaanalyses allowed the identification of novel non-HLA regions associated with T1D risk [43-47]. Such studies represented an important effort of the scientific community and are key to elucidate the genetic background of T1D, as they provide precious information to unravel the molecular mechanisms that underlie the disease pathogenesis. Major opportunities may result from the challenging interpretation of the data arising from GWAS, including (1) translation of the genetic signals associated with T1D into molecular mechanisms central to the disease pathogenesis, (2) detection of the causative risk variants and the dissection of their individual contribution to the disease and (3) translation of the aggregate genomic variation linked to the disease trait into tools that may assist individualized patient clinical management [18].

Latest novel non-HLA loci findings include the T1Dcentered association study by Onengut-Gumuscu et al. [48], in which they used ImmunoChip, a SNP microarray-centred on immune-disease-region, to unmask more than 40 non-HLA associated loci, 4 of which were novel associations. More recently, the same platform was applied to the currently largest and most ancestrally diverse genetic T1D cohort including 61,427 participants and yielding to 36 novel additional regions associated to genome-wide significance [49].
For some non-HLA T1D risk loci, a candidate gene has been identified, including the autoimmune regulator (AIRE) transcription factor, which is highly expressed in the thymus where it is implicated in the development of tolerance to selfantigens $[50,51]$. Other candidate genes are protein tyrosine phosphatase non-receptor type 2 (PTPN2), interleukin genes (such as IL4,IL13,IL4R,IL10), insulin receptor substrate 1 (IRS-1), inducible T cell costimulator (ICOS) and small ubiquitin-like modifier 4 (SUMO4), which modulate susceptibility to T1D or disease progression [12, 23].

Nonetheless, one of the main current challenges includes that of identifying the target gene or genes at each GWASassociated region and unravelling how their alleles affect downstream phenotypes. Such effort could in turn allow gaining deeper understanding of the mechanisms underlying T1D pathology and assess new druggable targets.

\section{Genetic Variants and the Non-coding Genome}

Most but not all disease-associated SNPs are found outside protein-coding sequences, mostly localized in at intergenic regions $[12,18,19,29]$, suggesting that T1D-associated genetic variation may impact regulatory functions rather than affecting the gene-coding potential. Genomic regulatory functions are highly dynamic and cell type-specific. Thus, identification of causal regulatory variants requires knowledge of tissue- and state-specific regulatory landscape of the cell types implicated in T1D pathogenesis [19].

During the last decades, the effort of single laboratories and of large consortia such as ENCODE and the Epigenome Roadmap, resulted in detailed annotation of the non-coding regions of the human genome for a large number of human tissues, including several relevant to T1D. Integration of such regulatory maps with GWAS data from different traits is pivotal to translate genetic association signals into molecular mechanisms [52]. Variants associated to complex diseases, including T1D, were found to overlap regulatory elements more than expected, including tissue-specific enhancers [19, $53,54]$. Fine mapping was subsequently used to prioritize disease-associated variants by integrating the association signal with genomic information such as gene expression, transcription factor-binding sites, DNA methylation, histone modifications or open chromatin regions. For a number of genetic association signals and different traits, these studies allowed the identification of functional risk variants affecting the tissue-specific regulatory code [18]. To date, there are dozens of examples of GWAS-associated variants affecting regulatory functions in different cell types and disease traits, including some in T1D [48, 55, 56]. As an example, one recent study [56] focused on a GWAS signal located at human chromosome 11q13.5 and shared by several autoimmune diseases, including Crohn's disease, ulcerative colitis, T1D and asthma. Integration of the genetic signal with cell-specific regulatory 
maps revealed that several associated variants in the locus interfere with the activation of a $\mathrm{CD} 4^{+}$regulatory $\mathrm{T}$ cell distal enhancer that induces the expression of LRRC32 and is required for $\mathrm{T}$ cell-mediated suppression of colitis.

Information on the genes affected by T1D regulatory variants is crucial to the development of therapeutic interventions targeting the disease pathogenic mechanisms. While regulatory maps allow prioritizing disease-associated GWAS variants falling in the non-coding genome, identification of the target gene(s) requires resolving regulatory relationships at the associated regions.

Most GWAS loci associated to a trait are conventionally named after the gene(s) with putative biological significance in linear proximity to the leading SNP (a variant in the locus showing the strongest association) of the region. Nevertheless, studies attempting to link distal regulatory elements to their target genes show that linear proximity provides a poor prediction. For example in one study, combination of chromatin capture and genome-editing techniques revealed that using distance in linear DNA as the only metric to link a gene promoter to a disease-relevant distal enhancer was not predictive of the correct target gene(s) for more than $70 \%$ of the T2Dassociated loci [57].

Therefore, the study of the 3D chromatin architecture is one approach that offers precious information on the gene targets at GWAS susceptibility loci, as regulatory elements are thought to physically interact with their target gene(s) to regulate gene expression. However, it remains largely unknown whether risk variants interfere with chromatin looping, leading to changes in gene regulation. A recent study generated high-resolution 3D chromatin maps in immature thymic $\mathrm{T}$ cells of mice with T1D predisposition [58]. The authors found that chromatin folding was altered at T1D risk-conferring loci, resulting in 3D chromatin interaction changes when compared to control mice. Moreover, they found that alterations in 3D genome architecture lead to gene expression changes in pancreas-infiltrating immune cells from T1D patients. Such observations indicate that T1D pathogenesis may involve changes in the $3 \mathrm{D}$ chromatin structure, likely altering regulatory interactions that lead to gene expression changes.

\section{Cell Types Implicated in T1D Pathogenesis}

The pathogenesis of complex diseases such as T1D typically implicates multiple cell types [18]. Classically, T1D GWAS variants have been mostly considered to impact the immune system. This hypothesis is in line with the autoimmune nature of the disease and is supported by multiple studies showing that T1D risk variants are enriched in enhancers active in $\mathrm{CD}^{+}$and $\mathrm{CD}^{+}{ }^{+}$cells $[48,49,59]$. Farh et al. [59], by integrating autoimmune disease GWAS data with regulatory genomic annotations, found that $\sim 90 \%$ of risk variants accumulate in non-coding regions. While $60 \%$ of these SNPs map to immune-cell enhancers, the authors reported only a reduced number of T1D variants overlapping islet enhancers. Similarly, Onengut-Gumuscu et al. [48] found a strong enrichment for T1D risk variants to overlap regulatory elements active in immune cell types, but not for pancreatic islet enhancers.

Work from other autoimmune diseases highlights that the cell types in which the risk allele exerts a pathogenic effect may include other non-immune cell types. By applying an alternative approach on a locus-by-locus basis, rather than computing conventional enrichment strategies, Factor et al. [60] uncovered several risk loci acting in oligodendrocytes and inducing an alteration of myelin production in the context of the pathogenesis of multiple sclerosis. These results do not contradict the current knowledge regarding the role of the immune system in disease aetiology. Instead, this work provides a better understanding of the disease pathogenesis and may help the development of more effective therapeutic approaches.

While it is now well established that alterations to the immune system are key in T1D pathogenesis, the concept that $\beta$ cells actively contribute to the development of the disease has gained traction during the last few years.

In support of this hypothesis, $\beta$-cell endoplasmic reticulum (ER) stress was shown to be present in T1D patients [61] and to temporally precede the development of hyperglycaemia in the T1D NOD mouse model [62]. Activation of these pathways has been observed in conjunction with $\beta$-cell HLA class I overexpression, which in turn serves as signal for immune-mediated $\beta$ cell destruction [63, 64]. Furthermore, cytokine-induced stress is coupled with the production of immunogenic peptides able to trigger or amplify the immune response $[5,65,66]$.

Such pathways may as well be activated upon cellular senescence. In T1D patients and NOD mice, a subset on $\beta$-cells was shown to acquire senescence-associated phenotype. Importantly, clearance of those senescent $\beta$ cells preserves $\beta$-cell mass and reduces diabetes incidence in mouse models [67].

Indeed, recent studies, described in the following sections, suggest that several T1D risk alleles may exert a pathogenic effect by interfering with $\beta$-cell regulatory networks and their response to an inflammatory environment $[7,20,55]$.

\section{T1D Risk and $\beta$-Cell Non-coding Functions}

During the past few years, the accumulating evidence for an active role of $\beta$-cells to T1D pathogenesis resulted in the engagement of different laboratories in attempting to map disease-associated variants to regulatory regions active in $\beta$-cells, as a means to characterize the mechanistic role of $\beta$-cells in T1D development. 


\section{Regulatory Maps of Pancreatic Islets in Resting Conditions}

Human pancreatic islet regulatory landscape has been linked consistently to T2D risk, since islet regulatory elements were shown to be enriched in T2D disease variants [57, 68-70]. In T1D, some studies reported limited overlap of diseaseassociated variants with islet regulatory elements [59]. However, most of the T1D genetic association signal coincides with regulatory elements active in immune cell populations $[48,59]$.

Being that the $\beta$-cell failure is a central event to the pathogenesis of both T1D and T2D, several research groups interrogated pancreatic islets regulatory networks in search of shared genetic contributions to the risk of developing the diseases. Such effort is in line with the " $\beta$-cell fragility" model, which proposes that a genetically determined increased risk of $\beta$-cell death or insulin secretion dysfunction may contribute to the risk of developing either T2D or T1D, especially in the presence of immunological and/or metabolic stress factors [71-74].

Aylward et al. [75] observed a shared genetic risk mostly involving variants affecting islet function and insulin secretion. Interestingly, the authors uncovered a candidate-shared variant located in the proximity of the gene GLIS3, which mapped to a pancreatic islet accessible chromatin site and showed allele-specific enhancer activity in mouse $\beta$-cells. Similar findings at the GLIS3 locus, although associating different variants, were observed in a study applying stringent statistical methods in a large cohort of patients, also aiming to uncover co-localization of T1D and T2D genetic signals. In this study, the authors extend their findings to four additional regions in proximity of the genes $P G M 1, T M E M 129, I N S$ and $B C A R 1 / C T R B 1$ [76]. Unlike for GLIS3, which shows concordant direction of effect, for these four additional signals, the effect of genetic variants in T1D and T2D was in opposite directions. Such important observations suggest that genetically identified drug targets would have exclusive efficacy in the treatment of one of the two diseases, making it key to find proper diagnostic tools to avoid misdiagnosis in older individuals.

Further insights into the role of GLIS3 and other T1D risk loci in pancreatic islets were provided by Inshaw et al. [77]. In this study, six HLA and six non-HLA risk alleles were associated with stronger effect sizes in T1D patients under 7 years of age, compared to $\geq 13$-year-old patients. The authors highlight the candidate gene GLIS3 to likely act through $\beta$-cells and $C T S H$ and $I K Z F 3$, which may act through pancreatic islets or other tissues. A T1D-associated variant at the CTSH locus (15q25.1) was shown to co-localize with a CTSH eQTL in which the risk allele is associated with the upregulation of the transcript.. An LD block of 103 variants was prioritized at the IKZF3 locus (17q12-q21.1) although further analyses, such as intersection with regulatory maps, are needed to identify functional variants. IKZF3 is a transcriptional repressor already implicated in asthma and other autoimmune diseases. Interestingly, the risk allele seems to exert an opposite direction-of-effect, as it increases susceptibility to autoimmunity but protects against asthma.

In conclusion, several studies uncovered examples of T1D variants acting through regulatory elements active in unchallenged pancreatic islets. Nevertheless, the number of potentially functional variants detected is relatively reduced when compared to studies showing that $>80 \%$ of T1D genes are expressed in pancreatic islets [78-80]. Such observation could in part be reconciled by expanding the repertoire of islet regulatory elements by charting state-specific regulatory maps in islet exposed to T1D-relevant stimuli.

\section{Regulatory Maps of Pancreatic Islets Exposed to External Stimuli}

The hypothesis that chromatin maps were static and cells responded to environmental changes through a preestablished set regulatory elements was challenged by Ostuni et al. [81], who instead showed that new regulatory elements, which they called latent enhancers, could appear in adult macrophages in response to external stimuli. In $\beta$ cells, some studies have revealed changes in their regulatory landscape after exposure of human islets to external stimuli $[55,82]$.

During the first phase of T1D, $\beta$-cells are exposed to a proinflammatory environment. It is thus logical to reason that such environment may affect the $\beta$-cell cis-regulatory landscape. Indeed, Ramos-Rodríguez et al. [55] observed significant chromatin remodelling in human islets and $\beta$-cells treated with IFN- $\gamma+$ IL- $1 \beta$. Exposure to these proinflammatory cytokines revealed a set of cytokine-induced regulatory elements which they named induced regulatory elements (IREs). Moreover, the activation of novel regulatory elements was coupled with the establishment of new enhancer-promoter contacts linking IREs to their putative target genes. In turn, IREs were associated with the upregulation of nearby genes and their corresponding proteins, which are involved in immune response and pathways implicated in T1D pathogenesis. Importantly IREs were shown to be enriched for T1D risk SNPs. At 9 associated loci, T1D risk variants were found to directly overlap an IRE, suggesting that they might interfere with the pancreatic islet response to a proinflammatory environment. In line with this hypothesis, the risk alleles of rs 78037977 (FASLG-TNFSF18 region) and rs 193778 (CIITA-DEXI-CLEC16-SOCS1 region) T1D risk variants were shown to affect in vitro IRE enhancer activity in human $\beta$-cells exposed to proinflammatory cytokines.

Using a similar approach, Colli et al. [83] studied early insulitis by exposing $\beta$-cells to IFN- $\alpha$. Similarly, IFN- $\alpha$ induced chromatin remodelling was associated with upregulation 
of nearby genes and their corresponding protein. The study of the IFN- $\alpha$-induced transcription factor binding sites induced by IFN- $\alpha$ exposure uncovered IRF and STAT as key drivers of the interferon signature in $\beta$-cells. Mining regulatory networks of the upregulated genes revealed two potential therapeutic interventions for reversing IFN- $\alpha$ deleterious effects on $\beta$-cells.

Both abovementioned studies take advantage of human pancreatic islets and a human $\beta$-cell line (EndoC- $\beta$ H1 [84]), to characterize $\beta$-cell responses to T1D-relevant environmental changes. However, models have limitations: (1) exposure to proinflammatory cytokines represent an over-simplified in vitro model of an inflammatory environment which is far from mirroring the in vivo occurrence of insulitis, (2) gene regulatory responses in the $\beta$-cell line might differ from that of the primary tissue and (3) studying responses in human pancreatic islets provides challenges when attempting to dissect the $\beta$-cell contribution to the observed regulatory changes.

Nevertheless, such observations suggest that T1Dassociated variants may act at a $\beta$-cell level in response to perturbations relevant to the disease pathogenesis (ex. inflammation), uncovering a novel potential mechanism linking genetic risk to T1D pathogenesis.

\section{Conclusions}

Understanding the genetic basis of T1D is key to provide new clinical tools for patient management, as well as to shed light on the disease pathogenesis in an effort of identifying new etiologically driven drugs.

To understand the implication of T1D-associated variants to the disease pathogenesis, it is essential to unravel their target cell type(s) and their state. While many T1Dassociated SNPs were shown to impact the immune system, several studies now reveal that a subset of T1D risk variants may act at the $\beta$-cell level, especially upon perturbations such as exposure to a proinflammatory environment. Such initial observations may be expanded by studying $\beta$-cell responses to a breath of disease-relevant conditions to fully characterize the pathology of T1D. Moreover, regulatory maps obtained from $\beta$-cells at different developmental stages or during senescence could be used to prioritize risk variants and reveal new insight into the pathogenesis of T1D and its genetic predisposition. $\beta$-cell enhancers containing T1D risk variants may also be active in other disease-relevant cell populations, such as $\mathrm{T}$ cells, thus making more difficult the dissection of the disease mechanisms.

Given the difficulty to access primary tissues from T1D patients in different T1D stages, in vitro models provide a key resource to decipher the role of $\beta$-cells in their own demise. However, such studies have to be considered with caution, as they use models that might not fully resemble the actual disease course. Current efforts to collect and study human islets from T1D patients, such as nPOD (Network for Pancreatic Organ Donors with Diabetes) consortia [85], may help to confirm and further investigate $\beta$-cell role in T1D. This, together with the advent of single-cell techniques, may allow improving the characterization of the islet cell populations through which T1D risk variants might be acting.

Shedding light on the genetic basis of $\beta$-cell fragility may open the path to solve critical disease mechanisms that could, in turn, be target of new therapeutic approaches.

Funding This review was supported by the Spanish Ministry of Economy and Competiveness (SAF2017-86242-R), EFSD/JDRF/Lilly Programme on Type 1 Diabetes Research, Premi Gonçal Lloveras i Vallès a l'Excelència en Investigació junior 2020 and Unidad María de Maeztu (MDM-2014-0370).

\section{Compliance with Ethical Standards}

Conflict of Interest The authors declare that they have no conflict of interest.

Open Access This article is licensed under a Creative Commons Attribution 4.0 International License, which permits use, sharing, adaptation, distribution and reproduction in any medium or format, as long as you give appropriate credit to the original author(s) and the source, provide a link to the Creative Commons licence, and indicate if changes were made. The images or other third party material in this article are included in the article's Creative Commons licence, unless indicated otherwise in a credit line to the material. If material is not included in the article's Creative Commons licence and your intended use is not permitted by statutory regulation or exceeds the permitted use, you will need to obtain permission directly from the copyright holder. To view a copy of this licence, visit http://creativecommons.org/licenses/by/4.0/.

\section{References}

1. International Diabetes Federation. IDF Diabetes Atlas, 9th edn. In: IDF Diabetes Atlas. 2019. https://www.diabetesatlas.org. Accessed 4 Sep 2020.

2. Mayer-Davis EJ, Lawrence JM, Dabelea D, Divers J, Isom S, Dolan L, et al. Incidence trends of type 1 and type 2 diabetes among youths, 2002-2012. N Engl J Med. 2017;376:1419-29.

3. Gomez-Lopera N, Pineda-Trujillo N, Diaz-Valencia PA. Correlating the global increase in type 1 diabetes incidence across age groups with national economic prosperity: a systematic review. World J Diabetes. 2019;10:560-80.

4. Todd JA. Etiology of type 1 diabetes. Immunity. 2010;32:457-67.

5. Eizirik DL, Colli ML, Ortis F. The role of inflammation in insulitis and beta-cell loss in type 1 diabetes. Nat Rev Endocrinol. 2009;5:219-26.

6. Ziegler A-G, Nepom GT. Prediction and pathogenesis in type 1 diabetes. Immunity. 2010;32:468-78.

7. Eizirik DL, Pasquali L, Cnop M. Pancreatic $\beta$-cells in type 1 and type 2 diabetes mellitus: different pathways to failure. Nat Rev Endocrinol. 2020;16:349-62. https://doi.org/10.1038/s41574-020-0355-7.

8. Roizen JD, Bradfield JP, Hakonarson H. Progress in understanding type 1 diabetes through its genetic overlap with other autoimmune diseases. Curr Diab Rep. 2015;15:102. 
9. Christoffersson G, von Herrath MG. A deeper look into type 1 diabetes - imaging immune responses during onset of disease. Front Immunol. 2016;7:313.

10. Redondo MJ, Jeffrey J, Fain PR, Eisenbarth GS, Orban T. Concordance for islet autoimmunity among monozygotic twins. N Engl J Med. 2008;359:2849-50.

11. Pociot F, Lernmark Å. Genetic risk factors for type 1 diabetes. Lancet. 2016;387:2331-9.

12. Pociot F. Type 1 diabetes genome-wide association studies: not to be lost in translation. Clin Transl Immunol. 2017;6:e162.

13. Ashley EA. Towards precision medicine. Nat Rev Genet. 2016;17:50722.

14. McCarthy MI. Painting a new picture of personalised medicine for diabetes. Diabetologia. 2017;60:793-9.

15. Chatterjee N, Shi J, García-Closas M. Developing and evaluating polygenic risk prediction models for stratified disease prevention. Nat Rev Genet. 2016;17:392-406.

16. Cano-Gamez E, Soskic B, Roumeliotis TI, et al. Single-cell transcriptomics identifies an effectorness gradient shaping the response of CD4+ T cells to cytokines. Nat Commun. 2020;11:1-15.

17. Sharp SA, Rich SS, Wood AR, Jones SE, Beaumont RN, Harrison JW, et al. Development and standardization of an improved type 1 diabetes genetic risk score for use in newborn screening and incident diagnosis. Diabetes Care. 2019;42:200-7.

18. Cano-Gamez E, Trynka G. From GWAS to function: using functional genomics to identify the mechanisms underlying complex diseases. Front Genet. 2020;11:1-21.

19. Inshaw JRJJ, Cutler AJ, Burren OS, Stefana MI, Todd JA. Approaches and advances in the genetic causes of autoimmune disease and their implications. Nat Immunol. 2018;19:674-84.

20. Størling J, Pociot F. Type 1 diabetes candidate genes linked to pancreatic islet cell inflammation and beta-cell apoptosis. Genes (Basel). 2017;8:1-12.

21. Cudworth AG, Woodrow JC. Letter: HL-A antigens and diabetes mellitus. Lancet. 1974;2:1153.

22. Polychronakos $\mathrm{C}, \mathrm{Li}$ Q. Understanding type 1 diabetes through genetics: advances and prospects. Nat Rev Genet. 2011;12:781-92.

23. Jerram S, Leslie RD. The genetic architecture of type 1 diabetes. Genes (Basel). 2017;8:209.

24. Koskinen MK, Mikk M-L, Laine A-P, Lempainen J, Löyttyniemi E, Vähäsalo P, et al. Longitudinal pattern of first-phase insulin response is associated with genetic variants outside the class II HLA region in children with multiple autoantibodies. Diabetes. 2020;69:12-9.

25. Noble JA, Valdes AM, Cook M, Klitz W, Thomson G, Erlich HA. The role of HLA class II genes in insulin-dependent diabetes mellitus: molecular analysis of 180 Caucasian, multiplex families. Am J Hum Genet. 1996;59:1134-48.

26. Howson JMM, Walker NM, Clayton D, Todd JA. Confirmation of HLA class II independent type 1 diabetes associations in the major histocompatibility complex including HLA-B and HLA-A. Diabetes Obes Metab. 2009;11(Suppl 1):31-45.

27. Nejentsev S, Howson JMM, Walker NM, et al. Localization of type 1 diabetes susceptibility to the MHC class I genes HLA-B and HLA-A. Nature. 2007;450:887-92.

28. Bjorkman PJ, Parham P. Structure, function, and diversity of class I major histocompatibility complex molecules. Annu Rev Biochem. 1990;59:253-88.

29. Nyaga DM, Vickers MH, Jefferies C, Perry JK, O’Sullivan JM. The genetic architecture of type 1 diabetes mellitus. Mol Cell Endocrinol. 2018;477:70-80.

30. Bell GI, Horita S, Karam JH. A polymorphic locus near the human insulin gene is associated with insulin-dependent diabetes melliitus. Diabetes. 1984;33:176-83.
31. Pugliese A, Zeller M, Fernandez AJ, Zalcberg LJ, Bartlett RJ, Ricordi C, et al. The insulin gene is transcribed in the human thymus and transcription levels correlated with allelic variation at the INS VNTR-IDDM2 susceptibility locus for type 1 diabetes. Nat Genet. 1997;15:293-7.

32. Bennett ST, Lucassen AM, Gough SC, Powell EE, Undlien DE, Pritchard LE, et al. Susceptibility to human type 1 diabetes at IDDM2 is determined by tandem repeat variation at the insulin gene minisatellite locus. Nat Genet. 1995;9:284-92.

33. Grant SFA, Wells AD, Rich SS. Next steps in the identification of gene targets for type 1 diabetes. Diabetologia. 2020;63:2260-9. https://doi.org/10.1007/s00125-020-05248-8.

34. Krummel MF, Allison JP. CD28 and CTLA-4 have opposing effects on the response of $\mathrm{T}$ cells to stimulation. J Exp Med. 1995;182:459-65.

35. Nisticò L, Buzzetti R, Pritchard LE, van der Auwera B, Giovannini $\mathrm{C}$, Bosi E, et al. The CTLA-4 gene region of chromosome $2 \mathrm{q} 33$ is linked to, and associated with, type 1 diabetes. Belgian Diabetes Registry. Hum Mol Genet. 1996;5:1075-80.

36. Ueda H, Howson JMM, Esposito L, Heward J, Snook, Chamberlain G, et al. Association of the T-cell regulatory gene CTLA4 with susceptibility to autoimmune disease. Nature. 2003;423:506-11.

37. Bottini N, Musumeci L, Alonso A, Rahmouni S, Nika K, Rostamkhani $\mathrm{M}$, et al. A functional variant of lymphoid tyrosine phosphatase is associated with type I diabetes. Nat Genet. 2004;36:337-8.

38. Smyth D, Cooper JD, Collins JE, Heward JM, Franklyn JA, Howson JMM, et al. Replication of an association between the lymphoid tyrosine phosphatase locus (LYP/PTPN22) with type 1 diabetes, and evidence for its role as a general autoimmunity locus. Diabetes. 2004;53:3020-3.

39. Vella A, Cooper JD, Lowe CE, Walker N, Nutland S, Widmer B, et al. Localization of a type 1 diabetes locus in the IL2RA/CD25 region by use of tag single-nucleotide polymorphisms. Am J Hum Genet. 2005;76:773-9.

40. Qu H-Q, Montpetit A, Ge B, Hudson TJ, Polychronakos C. Toward further mapping of the association between the IL2RA locus and type 1 diabetes. Diabetes. 2007;56:1174-6.

41. Concannon P, Onengut-Gumuscu S, Todd JA, Smyth DJ, Pociot F, Bergholdt R, et al. A human type 1 diabetes susceptibility locus maps to chromosome 21q22.3. Diabetes. 2008;57:2858-61.

42. Smyth DJ, Cooper JD, Bailey R, Field S, Burren O, Smink LJ, et al. A genome-wide association study of nonsynonymous SNPs identifies a type 1 diabetes locus in the interferon-induced helicase (IFIH1) region. Nat Genet. 2006;38:617-9.

43. Hakonarson H, Grant SFA, Bradfield JP, Marchand L, Kim CE, Glessner JT, et al. A genome-wide association study identifies KIAA0350 as a type 1 diabetes gene. Nature. 2007;448:591-4.

44. Burton PR, Clayton DG, Cardon LR, et al. Genome-wide association study of 14,000 cases of seven common diseases and 3,000 shared controls. Nature. 2007;447:661-78.

45. Todd JA, Walker NM, Cooper JD, et al. Robust associations of four new chromosome regions from genome-wide analyses of type 1 diabetes. Nat Genet. 2007;39:857-64.

46. Cooper JD, Smyth DJ, Smiles AM, Plagnol V, Walker NM, Allen JE, et al. Meta-analysis of genome-wide association study data identifies additional type 1 diabetes risk loci. Nat Genet. 2008;40:1399-401.

47. Barrett JC, Clayton DG, Concannon P, et al. Genome-wide association study and meta-analysis find that over 40 loci affect risk of type 1 diabetes. Nat Genet. 2009;41:703-7.

48. Onengut-Gumuscu S, Chen W-M, Burren O, et al. Fine mapping of type 1 diabetes susceptibility loci and evidence for colocalization of causal variants with lymphoid gene enhancers. Nat Genet. 2015;47: $381-6$. 
49. Robertson CC, Inshaw JRJ, Onengut-Gumuscu S, et al. Fine-mapping, trans-ancestral and genomic analyses identify causal variants, cells, genes and drug targets for type 1 diabetes. bioRxiv 2020.06.19.158071. 2020.

50. Liston A, Lesage S, Wilson J, Peltonen L, Goodnow CC. Aire regulates negative selection of organ-specific T cells. Nat Immunol. 2003;4:350-4.

51. Sabater L, Ferrer-Francesch X, Sospedra M, Caro P, Juan M, PujolBorrell R. Insulin alleles and autoimmune regulator (AIRE) gene expression both influence insulin expression in the thymus. $\mathrm{J}$ Autoimmun. 2005;25:312-8.

52. Mularoni L, Ramos-Rodríguez M, Pasquali L. The Pancreatic Islet Regulome Browser. Front Genet. 2017;8:1-8.

53. Hoffman MM, Ernst J, Wilder SP, Kundaje A, Harris RS, Libbrecht $\mathrm{M}$, et al. Integrative annotation of chromatin elements from ENCODE data. Nucleic Acids Res. 2013;41:827-41.

54. Schaub MA, Boyle AP, Kundaje A, Batzoglou S, Snyder M. Linking disease associations with regulatory information in the human genome. Genome Res. 2012;22:1748-59.

55. Ramos-Rodríguez M, Raurell-Vila H, Colli ML, Alvelos MI, Subirana-Granés M, Juan-Mateu J, et al. The impact of proinflammatory cytokines on the $\beta$-cell regulatory landscape provides insights into the genetics of type 1 diabetes. Nat Genet. 2019;51: $1588-95$.

56. Nasrallah R, Imianowski CJ, Bossini-Castillo L, et al. A distal enhancer at risk locus 11q13.5 promotes suppression of colitis by Treg cells. Nature. 2020. https://doi.org/10.1038/s41586-020-2296-7.

57. Miguel-Escalada I, Bonàs-Guarch S, Cebola I, et al. Human pancreatic islet three-dimensional chromatin architecture provides insights into the genetics of type 2 diabetes. Nat Genet. 2019;51:1137-48.

58. Fasolino M, Goldman N, Wang W, et al. Genetic variation in type 1 diabetes reconfigures the $3 \mathrm{D}$ chromatin organization of $\mathrm{T}$ cells and alters gene expression. Immunity. 2020;52:257-274.e11.

59. Farh KK-H, Marson A, Zhu J, Kleinewietfeld M, Housley WJ, Beik $\mathrm{S}$, et al. Genetic and epigenetic fine mapping of causal autoimmune disease variants. Nature. 2015;518:337-43.

60. Factor DC, Barbeau AM, Allan KC, et al. Cell type-specific intralocus interactions reveal oligodendrocyte mechanisms in MS. Cell. 2020;181:382-395.e21.

61. Marhfour I, Lopez XM, Lefkaditis D, Salmon I, Allagnat F, Richardson SJ, et al. Expression of endoplasmic reticulum stress markers in the islets of patients with type 1 diabetes. Diabetologia. 2012;55:2417-20.

62. Tersey SA, Nishiki Y, Templin AT, Cabrera SM, Stull ND, Colvin $\mathrm{SC}$, et al. Islet $\beta$-cell endoplasmic reticulum stress precedes the onset of type 1 diabetes in the nonobese diabetic mouse model. Diabetes. 2012;61:818-27.

63. Marroqui L, Dos Santos RS, Op de Beeck A, Coomans de Brachène $\mathrm{A}$, Marselli L, Marchetti $\mathrm{P}$, et al. Interferon- $\alpha$ mediates human beta cell HLA class I overexpression, endoplasmic reticulum stress and apoptosis, three hallmarks of early human type 1 diabetes. Diabetologia. 2017;60:656-67.

64. Morgan NG, Richardson SJ. Fifty years of pancreatic islet pathology in human type 1 diabetes: insights gained and progress made. Diabetologia. 2018;61:2499-506.

65. Gonzalez-Duque S, Azoury ME, Colli ML, et al. Conventional and neo-antigenic peptides presented by $\beta$ cells are targeted by circulating naïve $\mathrm{CD} 8+\mathrm{T}$ cells in type 1 diabetic and healthy donors. Cell Metab. 2018;28:946-960.e6.

66. Kracht MJL, van Lummel M, Nikolic T, Joosten AM, Laban S, van der Slik AR, et al. Autoimmunity against a defective ribosomal insulin gene product in type 1 diabetes. Nat Med. 2017;23:501-7.
67. Thompson PJ, Shah A, Ntranos V, Van Gool F, Atkinson M, Bhushan A. Targeted elimination of senescent beta cells prevents type 1 diabetes. Cell Metab. 2019;29:1045-1060.e10.

68. Pasquali L, Gaulton KJ, Rodríguez-Seguí SA, Mularoni L, MiguelEscalada I, Akerman İ, et al. Pancreatic islet enhancer clusters enriched in type 2 diabetes risk-associated variants. Nat Genet. 2014;46:136-43.

69. Cebola I, Pasquali L. Non-coding genome functions in diabetes. J Mol Endocrinol. 2015;56:R1-R20.

70. Parker SCJ, Stitzel ML, Taylor DL, Orozco JM, Erdos MR, Akiyama JA, et al. Chromatin stretch enhancer states drive cellspecific gene regulation and harbor human disease risk variants. Proc Natl Acad Sci U S A. 2013;110:17921-6.

71. Ikegami H, Fujisawa T, Ogihara T. Mouse models of type 1 and type 2 diabetes derived from the same closed colony: genetic susceptibility shared between two types of diabetes. ILAR J. 2004;45:268-77.

72. Nogueira TC, Paula FM, Villate O, Colli ML, Moura RF, Cunha DA, et al. GLIS3, a susceptibility gene for type 1 and type 2 diabetes, modulates pancreatic beta cell apoptosis via regulation of a splice variant of the BH3-only protein Bim. PLoS Genet. 2013;9: e1003532. https://doi.org/10.1371/journal.pgen.1003532.

73. Dooley J, Tian L, Schonefeldt S, Delghingaro-Augusto V, GarciaPerez JE, Pasciuto E, et al. Genetic predisposition for beta cell fragility underlies type 1 and type 2 diabetes. Nat Genet. 2016;48: 519-27.

74. Liston A, Todd JA, Lagou V. Beta-cell fragility as a common underlying risk factor in type 1 and type 2 diabetes. Trends Mol Med. 2017;23:181-94.

75. Aylward A, Chiou J, Okino M-L, Kadakia N, Gaulton KJ. Shared genetic risk contributes to type 1 and type 2 diabetes etiology. Hum Mol Genet. 2018. https://doi.org/10.1093/hmg/ddy314.

76. Inshaw JRJ, Sidore C, Cucca F, Stefana MI, Crouch DJM, McCarthy MI, Mahajan A, Todd JA. Divergent genetic effects for type 1 and type 2 diabetes at overlapping association signals. bioRxiv 2020.06.17.156778. 2020.

77. Inshaw JRJ, Cutler AJ, Crouch DJM, Wicker LS, Todd JA. Genetic variants predisposing most strongly to type 1 diabetes diagnosed under age 7 years lie near candidate genes that function in the immune system and in pancreatic $\beta$-cells. Diabetes Care. 2020;43:169-77.

78. Eizirik DL, Sammeth M, Bouckenooghe T, Bottu G, Sisino G, Igoillo-Esteve $\mathrm{M}$, et al. The human pancreatic islet transcriptome: expression of candidate genes for type 1 diabetes and the impact of pro-inflammatory cytokines. PLoS Genet. 2012;8:e1002552.

79. Marroqui L, Dos Santos RS, Fløyel T, Grieco FA, Santin I, Op de Beeck A, et al. TYK2, a candidate gene for type 1 diabetes, modulates apoptosis and the innate immune response in human pancreatic $\beta$-cells. Diabetes. 2015;64:3808-17.

80. Bergholdt R, Brorsson C, Palleja A, Berchtold LA, Fløyel T, BangBerthelsen $\mathrm{CH}$, et al. Identification of novel type 1 diabetes candidate genes by integrating genome-wide association data, proteinprotein interactions, and human pancreatic islet gene expression. Diabetes. 2012;61:954-62.

81. Ostuni R, Piccolo V, Barozzi I, Polletti S, Termanini A, Bonifacio $\mathrm{S}$, et al. Latent enhancers activated by stimulation in differentiated cells. Cell. 2013;152:157-71.

82. Aylward A, Okino M, Benaglio P, Chiou J, Beebe E. Glucocorticoid signaling in pancreatic islets modulates gene regulatory programs and genetic risk of type 2 diabetes. bioRxiv. 2020 . https://doi.org/10.1101/2020.05.15.038679.

83. Colli ML, Ramos-Rodríguez M, Nakayasu ES, Alvelos MI, Lopes $\mathrm{M}$, Hill JLE, et al. An integrated multi-omics approach identifies the 
landscape of interferon- $\alpha$-mediated responses of human pancreatic beta cells. Nat Commun. 2020;11:2584.

84. Ravassard P, Hazhouz Y, Pechberty S, Bricout-Neveu E, Armanet $\mathrm{M}$, Czernichow $\mathrm{P}$, et al. A genetically engineered human pancreatic $\beta$ cell line exhibiting glucose-inducible insulin secretion. J Clin Invest. 2011;121:3589-97.

85. Campbell-Thompson M, Wasserfall C, Kaddis J, Albanese-O'Neill A, Staeva T, Nierras C, et al. Network for pancreatic organ donors with diabetes (nPOD): developing a tissue biobank for type 1 diabetes. Diabetes Metab Res Rev. 2012;28:608-17.

Publisher's Note Springer Nature remains neutral with regard to jurisdictional claims in published maps and institutional affiliations. 